\title{
УГОЛОВНЫЙ ПРОЦЕСС
}

\section{УГОЛОВНО-ПРОЦЕССУАЛЬНЫЕ ПРАВОПРИМЕНИТЕЛЬНЫЕ АКТЫ}

\begin{abstract}
(С Муравьев Кирилл Владимирович (murki@list.ru), доктор юридических наук, доцент, начальник кафедры криминалистики, Омская академия Министерства внутренних дел Российской Федерации, 644092, Российская Федерация, г. Омск, пр. Комарова, 7.

Тема докторской диссертации: «Оптимизация уголовного процесса как формы применения уголовного закона». Автор более 100 научных и учебно-методических работ по проблемам уголовного судопроизводства, в том числе монографий: «Возбуждение уголовного дела в отношении лица, подозреваемого в совершении преступления» (2009), «Меры процессуального принуждения - особые средства уголовно-правового воздействия» (2017), «Оптимизация процессуальной формы применения уголовного закона» (2019). Является соавтором трех учебников по дисциплине «Уголовный процесс», семи учебных пособий.

Область научных интересов: взаимосвязь уголовного материального и процессуального права, правовой статус участников уголовного судопроизводства, совершенствование порядка рассмотрения сообщений о преступлениях, предварительного расследования и судебного разбирательства, оптимизация системы, условий и порядка применения мер процессуального принуждения.
\end{abstract}

\begin{abstract}
АННОТАЦИЯ
Процессуальная деятельность неоднородна, подразделяется на принятие процессуальных решений и осуществление уголовно-процессуальных действий. Обосновывается, что процессуальные решения и действия компетентных лиц уголовного производства, а также удостоверяющие их письменные документы могут именоваться уголовно-процессуальными актами. Уголовное судопроизводство представляет собой деятельность по применению норм УПК РФ, соответствующие процессуальные акты допустимо именовать правоприменительными. Ряд принимаемых в уголовном судопроизводстве промежуточных и основных решений являются также и актами применения уголовного закона, если имеет место закрепление материально-правовых условий для принятия соответствующих процессуальных решений в бланкетной норме УПК РФ с отсылкой к диспозиции либо санкции уголовно-правовой нормы или через использование общих формулировок уголовного закона, а также если в акте оформляется вывод о состоявшейся конкретизации уголовно-правового отношения.
\end{abstract}

Ключевые слова: процессуальные акты, документы, действия, решения, правоприменение.

Цитирование. Муравьев К. В. Уголовно-процессуальные правоприменительные акты // Юридический вестник Самарского университета. 2019. Т. 5. № 2. С. 75-80. DOI: https://doi.org/10.18287/2542-047X-2019-5-2-75-80. 


\title{
CRIMINAL PROCEDURE LAW-ENFORCEMENT ACTS
}

\begin{abstract}
(C) Muravev Kirill Vladimirovich (murki@list.ru), Doctor of Law, associate professor, head of the Department of Criminalistics, Omsk Academy of the Ministry of the Interior of the Russian Federation, 7, Komarov Avenue, Omsk, 644092, Russian Federation.

Subject of Doctoral thesis: «Optimization of the criminal process as a form of application of criminal law». Author of more than 100 scientific and educational works on the problems of criminal justice, including monographs: «The initiation of criminal proceedings against a person suspected of committing a crime» (2009), «Measures of procedural coercion are special means of criminal legal influence» (2017), «Optimization of the procedural form of application of criminal law» (2019). Co-author of three textbooks on the discipline «Criminal Procedure», seven tutorials.

Research interests: relationship of criminal material and procedural law, legal status of participants in criminal proceedings, improving the procedure for handling reports of crimes, preliminary investigations and court proceedings, optimization of the system, conditions and procedure for applying procedural coercive measures.
\end{abstract}

\begin{abstract}
Procedural activity is non-uniform, is subdivided into adoption of proceeding decisions and implementation of criminal procedure actions. It is proved that proceeding decisions and actions of competent persons of criminal proceedings and also written documents certifying them can be called as criminal procedure acts. Criminal proceedings represent activities for the use of norms of the Criminal Procedure Code of the Russian Federation, are admissible to call the relevant procedural acts law-enforcement. A number of the intermediate and main decisions accepted in criminal proceedings are as well acts of application of the criminal law if fixing of substantive conditions for adoption of the relevant proceeding decisions in blanket norm of the Criminal Procedure Code of the Russian Federation with reference to a disposition or the sanction of criminal norm or through use of the general wording of the criminal law takes place and also if in the act a conclusion about the taken place specification of the criminal relation is made out.
\end{abstract}

Key words: procedural acts, documents, actions, decisions, law enforcement.

Citation. Muravev K. V. Ugolovno-protsessual'nye pravoprimenitel'nye akty [Criminal procedure law-enforcement acts]. Iuridicheskii vestnik Samarskogo universiteta [Juridical Journal of Samara University], 2019, Vol. 5, no. 2, pp. 75-80. DOI: https://doi.org/10.18287/2542-047X-2019-5-2-75-80 [in Russian].

По вопросу о понятии и видах индивидуальных правоприменительных актов в общей теории права и отраслевых науках нет единого мнения.

Так, С. С. Алексеев, отмечая многозначность термина «правовой акт», понимает под ним документ, в котором формально закрепляется решение компетентного органа по юридическому делу [1, с. 192-193]. П. С. Элькинд указывает, что уголовно-процессуальные акты (в досудебных стадиях - протоколы, постановления, в судебных протоколы, определения и приговоры) - это письменные процессуальные документы, составленные в результате деятельности органов предварительного расследования или суда, которыми оформляется применение уголовно-процессуальных норм [2, с. 145-154].

В соответствии со вторым подходом индивидуальный правовой акт понимается и как действие (поведение) компетентного органа, и как документ, в котором это действие получило закрепление. Например, М. С. Строгович писал, что процессуальным актом может называться действие участ- ника судопроизводства, облеченное в соответствующую форму и закрепленное в процессуальном документе [3, с. 200]. Н. Г. Муратова указывает, что уголовно-процессуальный акт - это направленное на осуществление задач судопроизводства и проводимое в установленном законом порядке действие компетентного должностного лица, облеченное в письменную форму процессуального документа $[4$, с. 22]. Такое понимание соответствует и семантике указанного термина. В толковом словаре С. И. Ожегова и Н. Ю. Шведовой отмечается, что «акт» - это «единичное действие, а также отдельный поступок»; кроме того, «документ, удостоверяющий что-нибудь» (1 и 4 знач.) [5, с. 21].

Имеется и третья позиция по данному вопросу, согласно которой к процессуальным правоприменительным актам необходимо относить акты-документы, действия компетентных органов, а также решения, принимаемые в рамках уголовного производства. Так, по мнению А. С. Бахты, «вся деятельность по применению норм уголовно-процессуального права выражается в правопримени- 
тельных актах, т. е. в промежуточных или завершающих юридических действиях (включая принятие решений) уполномоченного на то органа (лица), порождающих те или иные последствия в ходе применения права» [6, с. 311]. Данная точка зрения учитывает разнообразные проявления уголовного судопроизводства, стремится к универсальности, а потому вызывает наибольшие симпатии.

В общем виде уголовно-процессуальное правоприменение представляет собой систему достаточно неоднородных действий. Схематично всю деятельность органов предварительного расследования и суда можно разграничить на организационную (носит вспомогательный, обеспечительный характер, не урегулирована УПК РФ) и процессуальную (выражается непосредственно в реализации уголовно-процессуальных норм). Последняя, в свою очередь, подразделяется на принятие процессуальных решений и осуществление уголовнопроцессуальных (следственных и иных процессуальных) действий.

Процессуальные решения являются важнейшей частью уголовно-процессуальной деятельности. Под ними следует понимать правовые акты, облеченные в установленную законом форму, в которых органы дознания, следователь, прокурор, судья или суд в пределах своей компетенции и в определенном законом порядке дают ответы по возникающим по делу вопросам и содержат властное волеизъявление о действиях, вытекающих из установленных обстоятельств и предписаний законов, направленных на достижение задач уголовного судопроизводства [7, с. 11]. Позицию о том, что уголовно-процессуальные решения представляют собой акт правоприменительной деятельности (индивидуальный акт применения права), поддерживает большое число юристов. При этом следует учитывать, что решения уголовного производства не всегда находят выражение в акте-документе. Многие из них (например, о приеме заявления о преступлении, о производстве осмотра места происшествия, о проведении допроса свидетеля и т. д.) не требуют письменного оформления. В юридическом деле о состоявшемся решении свидетельствует акт-документ, отражающий следующее за ним процессуальное действие.

Таким образом, полагаем, что подход авторов, при котором под уголовно-процессуальными актами понимаются акты-документы $(a)$, процессуальные действия (б) и процессуальные решения (в), является наиболее правильным. Он в наилучшей степени отражает разнообразные проявления деятельности органов предварительного расследования, прокурора и суда.

Основания и иные условия принятия решений, порядок проведения процессуальных действий, форма соответствующих актов-документов регламентируются УПК РФ. По этой причине уголовное судопроизводство представляет собой деятельность по применению норм уголовно-процессуального закона, а перечисленные уголовнопроцессуальные акты допустимо именовать правоприменительными.
Одновременно следует учитывать, что уголовный процесс является формой применения уголовного закона. Иначе говоря, он представляет собой деятельность уполномоченных государственных органов и должностных лиц, связанную с вынесением актов, которыми: удостоверяется соблюдение или правомерность использования уголовно-правовых норм; устанавливается законность и целесообразность их исполнения, а также справедливость уголовно-правового воздействия; разрешаются правовые вопросы, возникающие в связи с реализацией уголовного закона [8, с. 24]. Поэтому ряд решений уголовного судопроизводства представляют собой как акты уголовно-процессуального, так и уголовного правоприменения.

Значительное число индивидуальных актов выносится на основе именно уголовно-правовых норм. Например, в досудебном производстве квалификация деяния указывается в постановлении о возбуждении уголовного дела (п. 4 ч. 2 ст. 146 УПК РФ), в актах, которыми подозреваемые, обвиняемые информируются об осуществлении в отношении них уголовного преследования (п. 5 ч. 2 ст. 171 , п. 5 ч. 2 ст. $223^{1}$ УПК РФ), в решениях, оканчивающих досудебное производство (п. 4 ч. 2 ст. 213 , п. 4 ч. 1 ст. 220 , п. 5 ч. 1 ст. 225 , ч. 1 ст. $226^{7}$ УПК РФ), и т. д. При производстве в суде первой инстанции деянию дается уголовно-правовая оценка в постановлении о назначении судебного заседания (ч. 3 ст. 231 УПК РФ), в приговоре (п. 5 ст. 304, п. 3 ч. 1 ст. 308 УПК РФ), в других решениях.

При этом необходимо обратить внимание на трудность квалификации на досудебных стадиях производства, когда обстоятельства уголовного дела не установлены. В этот момент еще не определены не только конечный вывод (результат квалификации), но и условия для решения данной задачи. Иначе говоря, неизвестно, что необходимо квалифицировать [9, с. 169-170]. Поэтому уголовный правоприменительный процесс в большинстве случаев не может сводиться лишь к вынесению одного индивидуально-правового акта. Он предполагает принятие ряда решений, которые отражают «последовательное» применение уголовного закона.

Ученые - представители общей теории права отмечают, что вся правоохранительная деятельность государственных органов (являющаяся формой применения права) находит свое выражение в двух основных группах актов индивидуального значения. Первую группу составляют акты вспомогательного характера. Они отражают предварительные правоохранительные действия и издаются органами государства при исследовании обстоятельств каждого деяния, в котором обнаружены признаки неправомерности, а также при надзоре за соблюдением законности. Вторая группа объединяет акты основного характера, иллюстрирующие завершающие правоохранительные действия. Они содержат окончательную оценку того или иного деяния и устанавливают вид и меру правовой санкции, предусмотренной нормой 
права за нарушение содержащихся в ней предписаний, либо определяют отказ от применения правовой санкции $[10$, с. 8]. Таким образом, только в актах основного характера разрешается основной вопрос юридического процесса, ради которого велось производство - о существовании (законности) права государства на оказание принудительного уголовно-правового воздействия, целесообразности его использования и размере данного права (справедливости применения мер уголовно-правового воздействия) [11, с. 90].

По отношению к уголовному судопроизводству законодатель использует категорию «итоговое судебное решение», понимая под ним приговор, иное решение суда, вынесенное в ходе судебного разбирательства, которыми уголовное дело разрешается по существу (п. $53^{1}$ ст. 5 УПК РФ). Иные определения и постановления суда, за исключением итогового судебного решения, предлагается именовать «промежуточными судебными решениями» (п. $53^{2}$ ст. 5 УПК РФ).

Разрешение основного вопроса уголовного процесса допускается и в досудебном производстве. Например, при установлении состоявшейся реализации уголовно-правовых норм в форме соблюдения предусмотрены решения об отказе в возбуждении уголовного дела, о прекращении уголовного дела. Следовательно, категории «итоговое» и «промежуточное» (решение) вполне разумно распространять и на досудебное производство.

$\mathrm{C}$ учетом изложенного все индивидуальные процессуальные акты, которые выносятся на основе уголовно-правовых норм, можно дифференцировать на два вида. Первые - акты предварительного применения уголовного закона. Они отражают результаты продолжающегося процесса (промежуточные процессуальные решения). Вторые - акты основного применения уголовного закона. Их назначение - выступать условием для дальнейшей реализации норм УК РФ в форме исполнения или констатировать состоявшуюся реализацию уголовно-правовых норм в форме соблюдения или использования (итоговые процессуальные решения).

В деятельности компетентных органов можно разграничить применение норм материального или только процессуального права, причем в арсенале правоприменительного процесса самостоятельное применение уголовно-процессуальных норм занимает значительное место [12, с. 104]. Для вычленения индивидуальных актов применения уголовного закона из общего числа уголовнопроцессуальных решений требуется обращение к нормативному и содержательному критериям.

Процессуальные решения, связанные с применением уголовного закона, всегда предполагают наличие материально-правовых условий. Так, в ст. $25,28,28^{1}$ УПК РФ, регламентирующих условия прекращения уголовного дела (преследования), имеются соответствующие отсылки к ст. 75, 76, $76^{1}$ УК РФ. Может использоваться и иной способ - обращение к норме материального закона в общем виде. Например, согласно п. 3 ч. 1 ст. 24 УПК РФ, уголовное дело не может быть возбуждено, а начатое производство подлежит прекращению в связи с истечением сроков давности. В соответствии с ч. 1 ст. 108 УПК РФ заключение под стражу в качестве меры пресечения применяется в отношении подозреваемого или обвиняемого в совершении преступлений, за которые предусмотрено наказание в виде лишения свободы на срок свыше трех лет. Основанием для возбуждения уголовного дела является наличие достаточных данных, указывающих на признаки преступления (ч. 2 ст. 140 УПК РФ), и т. п.

В отдельных процессуальных актах, связанных с решениями, имеющими материально-правовые условия, уголовно-правовая оценка «переносится» из предшествующих документов (например, из постановления о возбуждении дела). Примерами могут служить: письменное указание прокурора о производстве дознания по преступлению небольшой или средней тяжести, которое не указано в п. 1 ч. 3 ст. 151 УПК РФ (ч. 4 ст. 150 УПК РФ); разрешение судьи о проведении контроля и записи телефонных и иных переговоров (ч. 1 ст. 186 УПК РФ) и т. п. Процессуальный акт в данных случаях не выступает в качестве промежуточного звена между нормой УК РФ, регулирующей неопределенные общественные отношения, и воплощением нормативного предписания в правомерное поведение субъектов регулируемого правоотношения должностных лиц государства. В этих ситуациях не образуется и каких-либо уголовно-правовых последствий. Фактически происходит использование уголовного закона, оно выступает средством организации осуществления уголовно-процессуальных норм [11, с. 33-65].

Таким образом, закрепления в бланкетной норме УПК РФ материально-правовых условий для принятия процессуальных решений недостаточно для того, чтобы данное решение могло именоваться актом применения уголовного закона. Требуется обращение к дополнительному (содержательному) критерию. Считаем правильной позицию исследователей о том, что акты применения закона должны быть направлены на установление, изменение или прекращение правоотношений, определение точного объема субъективных прав, юридических обязанностей их участников [13, с. 116-117]; что «применением правовых норм» может называться лишь такая деятельность, которая «сопряжена с организацией осуществления этих норм в правоотношениях и воздействием на обязанных лиц в этих отношениях» [14, с. 137].

Для практического применения меры уголовноправового воздействия к преступнику необходимо официально признать и зафиксировать соответствующее правоотношение. В первую очередь требуется определить юридический факт, его породивший, - событие преступления. Кроме того, следует выяснить, кто является субъектом уголовного правоотношения, т. е. установить то лицо, которое виновно в совершении преступления. 
Важно удостоверить и конкретное содержание данного отношения - отразить, какой уголовноправовой нормой оно предусмотрено.

Все эти задачи выполняются органами предварительного расследования, прокурором и судом. В различных процессуальных документах они фиксируют выявленное уголовно-правовое отношение в виде определенной квалификации совершенного деяния [9, с. 7-8]. При этом отдельные акты удостоверяют факт совершения деяния, содержащего признаки состава преступления (постановление о возбуждении уголовного дела). Другие - отражают конкретизацию субъекта (уведомление о подозрении в совершении преступления, постановление о привлечении в качестве обвиняемого и др.). Они содержат предварительную квалификацию преступления. Тем самым указанными актами конкретизируется и содержание правоотношения (права и обязанности относительно воздействия, определенного в той или иной норме УК РФ). Само же принудительное уголовно-правовое воздействие требует индивидуализации применения санкции уголовно-правовой нормы с учетом тяжести совершенного деяния, а также обстоятельств, характеризующих личность обвиняемого, смягчающих и отягчающих обстоятельств. Индивидуализация государственного воздействия в связи с совершением деяния, запрещенного уголовным законом, осуществляется в «основных» актах, отражающих завершающие правоохранительные действия (приговоре, а также иных итоговых судебных решениях). Как исключение она может воспроизводиться и в актах вспомогательного характера, которые выражают предварительные правоохранительные действия (в решениях о применении мер пресечения и некоторых иных мер процессуального принуждения) [15, с. 84]. воды:

С учетом изложенного, сделаем следующие вы-

1. Под уголовно-процессуальными актами следует понимать как сами процессуальные решения и действия компетентных лиц уголовного производства, так и удостоверяющие их письменные акты-документы.

2. Уголовное судопроизводство представляет собой деятельность по применению норм УПК РФ, соответствующие процессуальные акты допустимо именовать правоприменительными.

3. Ряд принимаемых в уголовном судопроизводстве промежуточных и основных решений являются также и актами применения уголовного закона. Для этого они должны соответствовать нормативному критерию (материально-правовые условия для принятия соответствующих процессуальных решений закрепляются в бланкетной норме УПК РФ с отсылкой к диспозиции либо санкции уголовно-правовой нормы или через использование общих формулировок уголовного закона) и содержательному критерию (в акте оформляется вывод о состоявшейся конкретизации уголовно-правового отношения).

\section{Библиографический список}

1. Алексеев С. С. Общая теория права: в 2 т. М., 1982. T. 2. 360 c. URL: https://ru.b-ok.org/book/523814/ c6f449.

2. Элькинд П. С. Толкование и применение норм уголовно-процессуального права. М.: Юрид. лит., 1967. 192 c. URL: http://lawlibrary.ru/izdanie3659.html.

3. Строгович M. С. Курс советского уголовного процесса: в 2 т. М.: Наука, 1968. T. 1. 472 с. URL: http://kalinovsky-k.narod.ru/b/strogovich/Strogovich. html.

4. Муратова Н. Г. Процессуальные акты органов предварительного расследования: вопросы теории и практики. Казань: Издательство Казанского университета, 1989. 118 c. URL: https://ru.b-ok.org/ book/3254084/a3a9e2.

5. Ожегов С. И., Шведова Н. Ю. Толковый словарь русского языка: 80000 слов и фразеологических выражений. 4-е изд., доп. М.: Азбуковник, 1999. 944 с.

6. Бахта А. С. Механизм уголовнопроцессуального регулирования: монография. Хабаровск, 2010. 376 c. URL: http://lawlibrary.ru/ izdanie $2167406 . \mathrm{html}$.

7. Лупинская П. А. Решения в уголовном судопроизводстве: теория, законодательство и практика. 2-е изд. М., 2010. 240 c. URL: https://www. lawmix.ru/commlaw/140.

8. Муравьев К. В. Оптимизация процессуальной формы применения уголовного закона: монография. M.: Проспект, 2019. 264 c. URL: https://litgid.com/ catalog/yuridicheskaya/optimizatsiya_protsessualnoy_ formy primeneniya ugolovnogo zakona monografiya.

9. Кудрявцев В. Н. Общая теория квалификации преступлений. 2-е изд., перераб. и доп. М.: Юристь, 2004. 304 c. URL: https://lawbook.online/knigarossii-pravo-ugolovnoe/obschaya-teoriya-kvalifikatsiiprestupleniy.html.

10. Бро Ю. Н. Проблемы применения советского права: учебное пособие. Иркутск: Изд-во ИГУ, 1980. 84 c. URL: http://lawlibrary.ru/izdanie7580.html.

11. Муравьев К. В. Оптимизация уголовного процесса как формы применения уголовного закона: дис. ... Д-ра юрид. наук: 12.00.09. Омск, 2017. 505 c. URL: http://www.dslib.net/kriminalprocess/optimizacija-ugolovnogo-processa-kak-formyprimenenija-ugolovnogo-zakona.html.

12. Зусь Л. Б. Правовое регулирование в сфере уголовного судопроизводства. Владивосток: Изд-во Дальневосточного университета, 1984. 145 с. URL: http://lawlibrary.ru/izdanie23213.html.

13. Цыганов В. И. Теория государства и права: тезисы лекций. Н. Новгород: Вектор ТиС, 2005. 201 с. URL: https://all-sci.net/prava-gosudarstva-teoriya/teoriyagosudarstva-prava-tezisyi-lektsiy.html.

14. Недбайло П. Е. Применение советских правовых норм. М.: Госюриздат, 1960. 150 с. URL: http://lawlibrary.ru/izdanie 7931.html.

15. Муравьев К. В. Меры процессуального принуждения - особые средства уголовно-правового воздействия: доктрина, применение, оптимизация: монография. Омск: Омская академия МВД России, 2017. 219 с. URL: http://kostacademy.kz/ novosti/2018/07/mpp_sredstvo_vozdeistviay_2017.pdf.

\section{References}

1. Alekseev S. S. Obshchaya teoriya prava: $v 2 t$. [General theory of law: in 2 Vols.]. M, 1982, Vol. 2, 
360 p. Available at: https://ru.b-ok.org/book/523814/ c6f449 [in Russian].

2. Elkind P. S. Tolkovanie $i$ primenenie norm ugolovno-protsessual'nogo prava [Interpretation and use of norms of law of criminal procedure]. M.: Yuridicheskaya literatura, 1967, 192 p. Available at: http://lawlibrary.ru/izdanie3659.html [in Russian].

3. Strogovich M. S. Kurs sovetskogo ugolovnogo protsessa: $v \begin{array}{lll}v & t \text {. [Course of the Soviet criminal }\end{array}$ proceedings: in 2 vols.]. M.: Nauka, 1968, Vol. 1, 472 p. Available at: http://kalinovsky-k.narod.ru/b/strogovich/ Strogovich.html [in Russian].

4. Muratova N. G. Protsessual'nye akty organov predvaritel'nogo rassledovaniya: voprosy teorii i praktiki [Procedural acts of bodies of preliminary investigation: issues of theory and practice]. Kazan: Izdatel'stvo Kazanskogo universiteta, 1989, 118 p. Available at: https://ru.b-ok.org/book/3254084/a3a9e2 [in Russian].

5. Ozhegov S. I., Shvedova N. Yu. Tolkovyi slovar' russkogo yazyka: 80000 slov $i$ frazeologicheskikh vyrazhenii. 4-e izd., dop. [Explanatory dictionary of the Russian language: 80000 words and phraseological expressions. 4 edition, enlarged]. M.: Azbukovnik, 1999, 944 p. [in Russian].

6. Bakhta A. S. Mekhanizm ugolovnoprotsessual'nogo regulirovaniya: monografiya [Mechanism of criminal procedure regulation: monograph]. Khabarovsk, 2010, 376 p. Available at: http://lawlibrary.ru/izdanie2167406.html [in Russian].

7. Lupinskaya P. A. Resheniya $v$ ugolovnom sudoproizvodstve: teoriya, zakonodatel'stvo i praktika. 2-e izd. [Decisions in criminal proceedings: theory, legislation and practice. $2^{\text {nd }}$ edition]. M., 2010, $240 \mathrm{p}$. Available at: https://www.lawmix.ru/commlaw/140 [in Russian].

8. Muravev K. V. Optimizatsiya protsessual'noi formy primeneniya ugolovnogo zakona: monografiya [Optimization of a procedural form of application of the criminal law: monograph]. M.: Prospect, 2019, 264 p. Available at: https://litgid.com/catalog/yuridicheskaya/ optimizatsiya protsessualnoy formy primeneniya ugolovnogo zakona monografiya [in Russian].
9. Kudryavtsev V. N. Obshchyaa teoriya kvalifikatsii prestuplenii. 2-e izd., pererab. $i$ dop. [General theory of qualification of crimes: $2^{\text {nd }}$ edition, revised and enlarged]. M.: Yurist", 2004, 304 p. Available at: https://lawbook. online/kniga-rossii-pravo-ugolovnoe/obschaya-teoriyakvalifikatsii-prestupleniy.html [in Russian].

10. Bro Yu. N. Problemy primeneniya sovetskogo prava: uchebnoe posobie [Problems of application of the Soviet right: training manual]. Irkutsk: Izd-vo IGU, 1980, 84 p. Available at: http://lawlibrary.ru/izdanie7580.html [in Russian].

11. Muravev K. V. Optimizatsiya ugolovnogo protsessa kak formy primeneniya ugolovnogo zakona: dis. ... d-ra yurid. nauk: 12.00.09 [Optimization of criminal proceedings as forms of application of the criminal law: Doctoral of Law thesis: 12.00.09]. Omsk, 2017, 505 p. Available at: http://www.dslib.net/kriminalprocess/optimizacija-ugolovnogo-processa-kak-formyprimenenija-ugolovnogo-zakona.html [in Russian].

12. Zus L. B. Pravovoe regulirovanie $v$ sfere ugolovnogo sudoproizvodstva [Legal regulation in the sphere of criminal proceedings]. Vladivostok: Izd-vo Dal'nevostochnogo universiteta, 1984, 145 p. Available at: http://lawlibrary.ru/izdanie23213.html [in Russian].

13. Tsyganov V. I. Teoriya gosudarstva i prava: tezisy lektsii [Theory of state and law: theses of lectures]. N. Novgorod: Vektor TiS, 2005, 201 p. Available at: https://all-sci.net/prava-gosudarstva-teoriya/teoriyagosudarstva-prava-tezisyi-lektsiy.html [in Russian].

14. Nedbaylo P. E. Primenenie sovetskikh pravovykh norm [Use of the Soviet precepts of law]. M.: Gosyurizdat, 1960, 150 p. Available at: http://lawlibrary. ru/izdanie7931.html [in Russian].

15. Muravev K. V. Mery protsessual'nogo prinuzhdeniya - osobye sredstva ugolovno-pravovogo vozdeistviya: doktrina, primenenie, optimizatsiya: monografiya [Measures of procedural coercion - special means of criminal influence: doctrine, application, optimization: monograph]. Omsk: Omskaya akademiya MVD Rossii, 2017, 219 p. Available at: http:// kostacademy.kz/novosti $/ 2018 / 07 / \mathrm{mpp}$ sredstvo_ vozdeistviay_2017.pdf [in Russian]. 